\title{
CELLULAR THERAPY REVERSES MYOCARDIAL DYSFUNCTION
}

C. Rajnoch, MSc

J.-C. Chachques, MD, PhD

A. Berrebi, MD

P. Bruneval, MD

M.-O. Benoit, MD

A. Carpentier, MD, $\mathrm{PhD}$

For related editorial, see p. 835 .
Objectives: Cellular cardiomyoplasty refers to the implantation of autologous skeletal muscle cells into the myocardium to reinforce its structure and function. In this study a reproducible method for the creation of a myocardial lesion was developed. The functional benefit of cell implantation was evaluated by 2-dimensional echocardiography for global contraction and color kinesis echocardiography, which allows the precise assessment of the regional contraction.

Methods: A left ventricular intramyocardial injection with snake cardiotoxin was carried out on a sheep model to induce a well-delineated transmural lesion. Three weeks later, the lesion was assessed by echocardiography. Thereafter, autologous skeletal muscle cells or culture media (control) were injected into the lesion. Two months after cell implantation, the myocardial contraction was again evaluated by echocardiography and the implanted cells were analyzed by a fast myosin heavy chain antibody.

Results: 1. The snake cardiotoxin produced a well-delineated transmural lesion in all animals. 2. Echocardiographic studies showed a significant improvement in global and regional left ventricular function in cell-treated sheep. 3. Histologic analyses demonstrated satellite cell survival at the periphery of the lesions.

Conclusion: Satellite cells implanted in a cardiotoxin-induced myocardial lesion survived for a 2-month period and were associated with a significant functional improvement of both local and global contraction. (J Thorac Cardiovasc Surg 2001;121:871-8)
I $\mathrm{n}$ the United States, an estimated 12 million persons have coronary heart disease, of whom 7 million are affected by myocardial infarction and 4.6 million by congestive heart failure (American Heart Association 1999 Heart and Stroke statistical update). As in many other developed countries, cardiovascular disease is a leading health problem and a predominant cause of death. Consequently, there is a desperate need for awareness, prevention, medication, and surgical treatments.

Cardiac transplantation, which is an efficient solution to this problem, is limited by a shortage of donors, com-

From the Laboratory of Cardiac Grafts and Prostheses, University of Paris VI and Broussais Hospital, Paris, France.

This work was supported by a Training and Mobility grant from the European Union (ERB4001GT957737), by the Alain Carpentier Foundation, and by the University of Paris VI.

Copyright (c) 2001 by The American Association for Thoracic Surgery

$0022-5223 / 2001 \$ 35.00+0 \quad \mathbf{1 2 / 6 / 1 1 2 9 3 7}$

doi: $10.1067 / \mathrm{mtc} .2001 .112937$ plications of immunosuppression, and graft failure. As an alternative, dynamic cardiomyoplasty was developed in our laboratory ${ }^{1}$ and clinically applied in $1985 .^{2}$ The principle of dynamic cardiomyoplasty is the use of an electrically stimulated skeletal muscle that is partially wrapped around the heart to restore or augment ventricular contraction. This surgical procedure provided evidence that an autologous skeletal muscle graft could be adapted to perform cardiac work and enhance cardiac function. ${ }^{3}$ Marelli and associates ${ }^{4}$ and $\mathrm{Chiu}^{5}$ extended this method by developing a less-invasive technique, called cellular cardiomyoplasty, in which satellite cells or undifferentiated myoblasts were cultured from a skeletal muscle fragment and implanted into the myocardium.

Over the past 7 years, primary myoblasts have been grafted into cryoinjured myocardium of rats, ${ }^{6-8}$ rabbits, ${ }^{9-12}$ and dogs. $., 13,14$ In this study, autologous satellite cells were implanted in a novel model of myocardial injury caused by snake cardiotoxin injection. ${ }^{15}$ The aims of this study were to show survival and differenti- 
ation of satellite cells in the injured areas of the sheep myocardium, to assess changes in global function by 2dimensional echocardiography, and to assess regional function by color kinesis echocardiography.

\section{Materials and methods}

The animal model. Fifteen sheep weighing $31 \pm 6 \mathrm{~kg}$ were divided into 4 groups. In group $1(\mathrm{n}=3)$ a myocardial lesion was effected. In group $2(n=3)$, which served as a control for group $1,0.9 \%$ sodium chloride was injected into healthy myocardium. In group $3(n=6)$, myocardial injury was induced and satellite cell implantation was carried out 3 weeks later. In group $4(n=3)$, which served as a control for group 3, cells were replaced by culture medium. All animals were treated according to the guidelines of the French National Institute of Health and Medical Research (INSERM).

Anesthetic and postoperative management. All sheep were deprived of drink and food for 24 hours before the operation. A premedication of $150 \mathrm{mg}$ acepromazine (Vetranquil; Sanofi-Synthelabo, Paris, France) was injected intramuscularly 30 minutes before propofol (Diprivan; Astra-Zeneca, London, United Kingdom) was injected intravenously into the left jugular vein at a concentration of $6 \mathrm{mg} / \mathrm{kg}$ body weight. The intubation was performed with an endotracheal probe number 7 . Ventilation was assured with a Siemens 900C respirator (Siemens, Munich, Germany) using the following parameters: a volume of 10 $\mathrm{mL} / \mathrm{kg}$ body weight, a frequency of 24 breaths $/ \mathrm{min}$, and an inspired oxygen fraction of $60 \%$. The anesthetic was maintained by inhalation of isoflurane (Forene; Abbott Laboratories, North Chicago, Ill) at $1 \%$ to $2 \%$. A gelatin solution (Plasmion; Fresenius France Pharma, Sevres, France) was installed as a standard procedure.

Postoperative management of the sheep consisted of cefazolin (Panpharma NV, Gent, Belgium) antibiotics injected intramuscularly at $1 \mathrm{~g}$ a day over a 1 -week period.

Skeletal muscle explantation and myocardial injury. A $1 \mathrm{~cm}^{3}$ skeletal muscle fragment was explanted from the left posterior femoral biceps of each sheep under sterile conditions. The biopsy tissue was kept in Hanks balanced salt solution (Gibco BRL, Life Technologies, Inc, Rockville, $\mathrm{Md})$ at $4^{\circ} \mathrm{C}$ until cell culture was started. The operative wound was closed.

A myocardial injury was induced in groups 1,3 , and 4 . The heart was exposed through a left thoracotomy in the fifth intercostal space. Next, $3 \mathrm{mg}$ of snake toxin from Naja mossambica mossambica (Sigma Chemical Co, St Louis, Mo) was dissolved in $1.5 \mathrm{~mL}$ sodium chloride $(0.9 \%)$ and injected with a disposable syringe connected to a Huber curved needle (LPI, SA, Bornel, France) into the left ventricular myocardium to induce myocardial injury. The site of the injury was marked with 3-0 Tevdek suture (Genzyme Surgical Products, Tucker, Ga) secured with metal ligating clips (Peters Medico-Surgical Materials, Bobigny, France). Each sheep was monitored by electrocardiography and the arterial systemic pressure was measured during the car- diotoxin injection. Thereafter, a drain was placed in the pleural cavity, and the pericardium, the thorax, the muscles, and the skin were closed. The drain was removed as soon as the sheep started spontaneous respiration.

The severity of the myocardial injury was expressed in cardiac troponin I levels ${ }^{16,17}$ and was measured 2 hours preoperatively and up to 6 days after myocardial injury in groups 1 and 2. The quantitative determination of cardiac troponin I levels in sheep serum was assessed with a cardiac troponin I fluorometric enzyme immunoassay (Stratus; Dade Behring, Inc, Deerfield, Ill). The detection limit was $0.3 \mathrm{ng} / \mathrm{mL}$.

Satellite cell isolation and culture. The explanted skeletal muscle fragments were washed in phosphate-buffered saline solution (PBS; Gibco). Adipose tissue and fascia were removed and the muscle was minced with scissors. The muscle fragments were washed in PBS until the supernatant remained clear. Centrifugation (Sigma 3K10, Bioblock) was carried out at $300 \mathrm{~g}$ for 5 minutes. The PBS was replaced with $20 \mathrm{~mL}$ of $0.25 \%$ trypsin-ethylenediaminetetraacetic acid (EDTA) (Gibco) and placed in a $37^{\circ} \mathrm{C}$ shaking water bath. After 40 minutes the fragments were forced through a $10-\mathrm{mL}$ disposable pipette. Once aspiration occurred easily, cells were filtered through a 40- $\mu \mathrm{m}$ nylon cell strainer (Polylabo SA, Geneva, Switzerland). Remaining muscle fragments on the filter were again subjected to enzymatic and mechanical digestion.

Fetal calf serum (1 mL) (FCS; Gibco) was added to the filtrate and the solution was centrifuged at $300 \mathrm{~g}$ for 20 minutes. The resulting cell pellets were pooled in $10 \mathrm{~mL}$ fresh complete culture medium: 79\% Ham-F12 medium, 20\% FCS, and $1 \%$ penicillin/streptomycin (Gibco), and plated in a 100$\mathrm{mm}$ Petri dish. Cell cultures were incubated at $37^{\circ} \mathrm{C}$ in a humidified atmosphere containing 5\% carbon dioxide. Passaging of the cultures (1:5 split) was carried out at subconfluency to avoid the occurrence of myogenic differentiation at higher densities. During the first passage, pre-plating was applied, which is based on the quicker attachment of fibroblasts compared with satellite cells. The satellite cells were implanted on the third passage.

The number of satellite cells in the primary culture was determined by immunofluorescence with a desmin primary antibody (1:20, Sigma) followed by FluoroLink Cy3 (1:200, Amersham Pharmacia Biotech, Piscataway, NJ) as a second antibody.

Satellite cell preparation and implantation. Before cell implantation, the growth medium of each sheep satellite cell culture was tested aerobically and anaerobically in broth for its sterility. The Petri dishes $(100 \mathrm{~mm})$ containing about $1 \times$ $10^{6}$ cells each were washed with PBS. On detachment of the cells using $2 \mathrm{~mL}$ trypsin-EDTA, $2 \mathrm{~mL}$ of complete culture medium was added to each cell suspension. The contents of the 25 culture dishes were pooled and spun at $300 \mathrm{~g}$ for 15 minutes. The supernatant was removed and replaced with 20 $\mathrm{mL}$ of PBS. The cell concentration and viability were determined with Trypan blue (Gibco) using a Neubauer hemacytometer (Polylabo). The calculated volume of cell suspension containing $2 \times 10^{7}$ cells was transferred to a $50-\mathrm{mL}$ tube and centrifuged at $300 \mathrm{~g}$ for 5 minutes. The final cell pellet was 


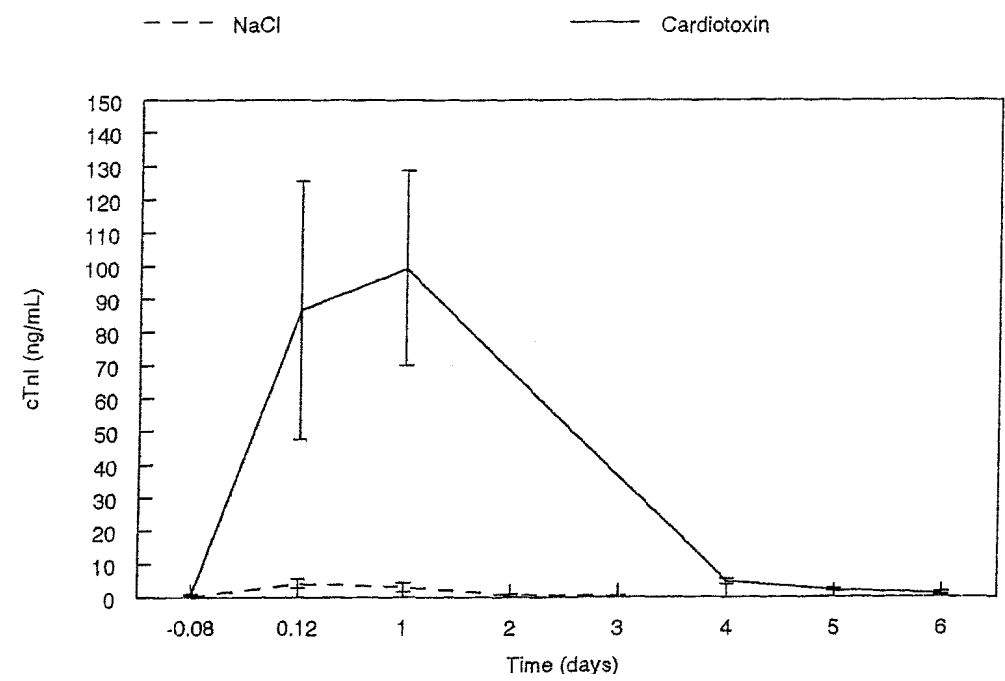

Fig 1. Cardiac troponin I levels measured in sheep serum 2 hours preoperatively until 6 days after a left ventricular cardiotoxin injection or sodium chloride as a control.

resuspended in $0.5 \mu \mathrm{L}$ of $0.5 \%$ bovine serum albumin (BSA; Sigma) diluted in Ham-F12 culture medium.

Three weeks after myocardial injury, satellite cells (group 3 ) or cell culture media containing $0.5 \%$ BSA (group 4) were injected into the left ventricular lesion. The heart was exposed by sternotomy. The injured site was identified by a suture and metal ligating clips (Peters), which were placed at the time of the injury. Satellite cells or control media were then injected with a 1-mL syringe guided by echocardiography with color kinesis to assure intramyocardial spreading of the solution. Thereafter, 2 thoracic drains were placed in the pleural cavity and the thorax was closed with metal wires (Peters). The wound was further closed in layers. The drains were removed at the time of extubation.

Echocardiography with color kinesis. Echocardiography with color kinesis (Sonos 5500; Hewlett-Packard Company, Palo Alto, Calif) is a new technique based on acoustic quantification, which allows the precise measurement of the regional wall motion. Color kinesis analyzes regional backscatter in each acoustic frame in real time and classifies each pixel as either blood or myocardial tissue. Pixel transitions from blood to tissue during systole are detected and color-encoded. Color overlays are updated on a frame-byframe basis by adding one color at a time ( 30 frames per second). Thus, a single end-systolic frame provides an integrated display of the timing and magnitude of endocardial wall motion. ${ }^{20}$

Regional wall motion measurements were carried out before cell implantation (group 3) or control medium injection (group 4) at 3 weeks, as well as 11 weeks after myocardial injury, with the aid of a 7-MHz transducer in the epicardial position. End-systolic frames were used for analysis to obtain quantitative information because they contain the entire spatial and temporal histories of the systolic endocardial excursion. Color-encoded images obtained from the short-axis and apical 4-chamber views were automatically divided into wedge-shaped segments with the customdesigned software. These segmentation schemes were used to minimize the variability caused by individual differences in left ventricular orientation at end-systole and therefore facilitate intersubject comparisons. Regional wall motion was then assessed by computing the pixel counts in each left ventricular segment. The segments were normalized by the corresponding regional end-systolic area to take into account intersegmental geometric differences and to quantify the regional fractional area change for each consecutive frame.

In comparison with the regional wall motion, the global cardiac function was measured at the same time points in the 2dimensional mode. The global parameters included the left ventricular end-diastolic and end-systolic diameters, the shortening fraction, the end-diastolic and end-systolic volumes, and the ejection fraction. The ejection fraction and shortening fraction were calculated by the Teicholz method and based on the left ventricular end-systolic and end-diastolic diameters. All values were expressed as the mean \pm standard deviation and statistical Student $t$ tests were applied to the results.

Histology. All sheep were euthanized 11 weeks after myocardial injury. The heart was exposed through a sternotomy. Heparin $(10,000 \mathrm{IU})$ and $2 \mathrm{~mL}$ of $4 \%$ papaverine were injected intravenously. Thereafter, $20 \mathrm{~mL}$ of $10 \%$ potassium chloride was injected intravenously and the beating heart was excised. The site of the myocardial injury was identified and dissected. All heart biopsy specimens were frozen in liquid nitrogen-cooled isopentane (Rectapur; Prolabo). Frozen biopsy tissue was stored at $-80^{\circ} \mathrm{C}$ until processed on a cryostat (AM 500; Microm, Francheville, France). The tissue was cut into $10 \mu \mathrm{m}$ sections. Every 10th and 11th section was colored with hematein-eosin and Masson's trichrome stains, respectively. If cells were observed in the myocardial lesion of these sections, serial sections were tested with a fast myosin heavy chain (MHC) antibody (MY-32; Sigma), which is specific for the skeletal isoform of adult fast MHC. 
Table I. Two-dimensional echocardiographic analysis showing global functional results (mean $\pm S D$ ) for cell-treated sheep

\begin{tabular}{lccc} 
& \multicolumn{2}{c}{ Cell-treated group 3 } & P value: Pre vs post \\
\cline { 2 - 3 } & Preimplantation & Postimplantation & $.001^{*}$ \\
LVEDD $(\mathrm{mm})$ & $41.17 \pm 3$ & $37.50 \pm 3$ & $.001^{*}$ \\
LVESD $(\mathrm{mm})$ & $31.50 \pm 3$ & $24.50 \pm 4$ & $.007^{*}$ \\
SF $(\%)$ & $23.50 \pm 5$ & $35.33 \pm 6$ & $.0003^{*}$ \\
EDV $(\mathrm{mL})$ & $77.00 \pm 10$ & $61.50 \pm 10$ & $.002^{*}$ \\
ESV $(\mathrm{mL})$ & $39.83 \pm 10$ & $22.00 \pm 8$ & $.005^{*}$ \\
EF $(\%)$ & $47.17 \pm 8$ & $65.00 \pm 8$ & \\
\hline
\end{tabular}

Measurements were taken 3 and 11 weeks after myocardial injury. LVEDD, Left ventricular end-diastolic dimension; $L V E S D$, left ventricular end-systolic dimension; $S F$, shortening fraction; $E D V$, end-diastolic volume; $E S V$, end-systolic volume; $E F$, ejection fraction.

*All parameters were statistically significant.

The sections treated with MHC antibody were first fixed in ethanol for 15 minutes. Unspecific sites were blocked with $10 \%$ FCS in PBS for 30 minutes. The sections were then incubated with the primary antibody (1:400) in $0.1 \%$ FCS for 1 hour, followed by incubation with the secondary antibody, FluoroLink Cy3-labeled goat anti-mouse immunoglobulin G $(\mathrm{H}+\mathrm{L})(1: 200$, Amersham Pharmacia Biotech) in $0.1 \%$ FCS for 30 minutes. Fluorescence was revealed with an inverted fluorescent microscope (Nikon Eclipse TE300; Nikon Inc, Melville, NY) using a rhodamine filter.

\section{Results}

Cell culture. Before satellite cell implantation into the myocardium, cell culture conditions were evaluated. The primary skeletal muscle cell cultures contained about $50 \%$ myoblasts as determined with desmin immunofluorescence. All cultures showed $99 \%$ viability before implantation by means of the trypan blue exclusion assay. In addition, all cell culture media taken from the cultures before implantation tested negative for aerobic and nonaerobic bacterial contaminations.

Myocardial injury. The sheep of groups 1, 3, and 4 underwent myocardial injury by a left ventricular injection of the snake cardiotoxin Naja mossambica mossambica with $100 \%$ survival. No significant changes were detected during hemodynamic or pressure measurements at the time of injection.

Cardiac troponin I was chosen as an indicator of myocardial infarction. Cardiac troponin I values were expressed as the mean \pm standard deviation in Fig 1 . Blood samples were taken from groups 1 and 2, 2 hours preoperatively and up to 6 days after cardiotoxin injection. The cardiotoxin induced a maximum troponin response in group 1 of $99.5 \mathrm{ng} / \mathrm{mL} 24$ hours after intramyocardial injection and returned to baseline levels after 4 days. The control group (group 2) reached a maximum cardiac troponin I concentration of 4.2 $\mathrm{ng} / \mathrm{mL} 3$ hours after injection and returned to baseline values after 2 days.

Macroscopically, a local area of necrosis was consistently observed in the myocardium at the site of cardiotoxin injection in groups 3 and 4 before cell implantation or control medium injection, respectively, after 3 weeks. Eleven weeks after cardiotoxin injection, the area of necrosis had developed into an approximately $2-\mathrm{cm}^{3}$ transmural scar (Fig 2, A). Light microscopic observations showed a replacement of healthy myocardium with adipose fibrous tissue in the lesion (Fig 2, B) and the inflammatory response was extremely low. In addition, a distinct boundary was noted between healthy and injured tissue. In the periphery of the lesion, the cardiomyocytes were often hypertrophic.

Echocardiography with color kinesis. The percentage of end-systolic area of the regional left ventricular wall motion, expressed as regional fractional area change, showed a significant increase in regional function from $24 \% \pm 2.8 \%$ to $48 \% \pm 9.3 \%(P<.05)$ in the cell-treated group, compared with a nonsignificant increase from $23.3 \% \pm 5.5 \%$ to $30 \% \pm 4.0 \%$ in the control group 11 weeks after myocardial injury. The colorencoded images, using backscatter, identified the pixel transition from tissue to blood, which were updated on a frame-by-frame basis resulting in color overlays. An example is given in Fig 2, $C$ and $D$. This figure represents the regional wall motion of 1 sheep from group 3 observed 3 weeks after myocardial injury (Fig 2,C) and 2 months after cell implantation (Fig 2,D). A visual comparison in segmental contraction can be made due to the color overlays. After cell implantation, a recovery in regional contraction is noted (Fig 2,D) compared with the limited contraction before cell implantation (Fig 2, C). 


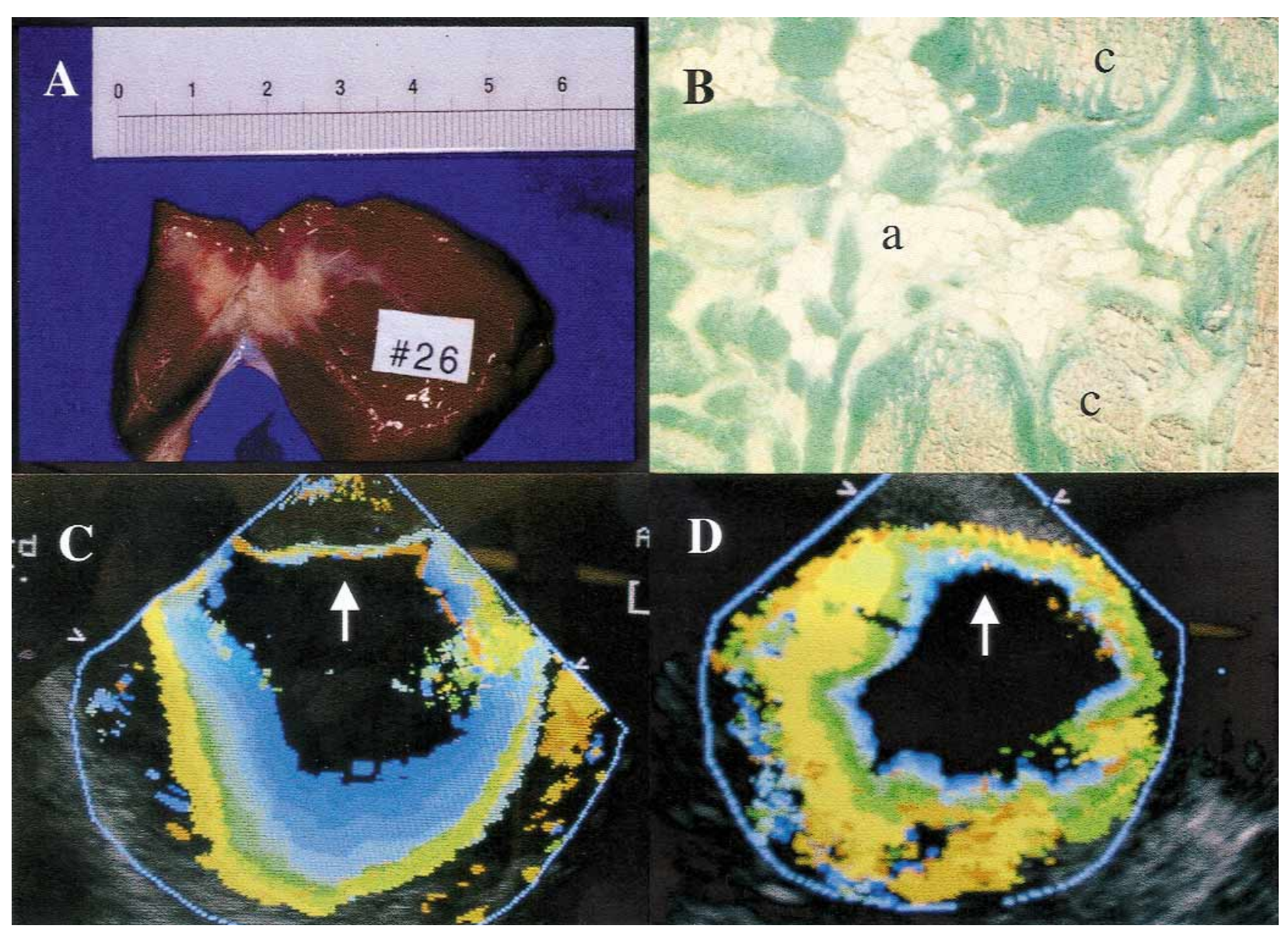

Fig 2. A, Well-defined transmural lesion produced by a cardiotoxin injection into the myocardium of a sheep. B, Microscopic section of the myocardial lesion stained with Masson trichrome showing cardiomyocytes $(c)$ on the periphery and fibrous tissue (green) and adipocytes $(a)$ in the lesion (magnification $\times 10$ ). $\mathbf{C}$, Echocardiography with color kinesis showing few color overlays in the akinetic region (arrow) of the left ventricular anterior wall in a 3-week-old myocardial lesion. D, Increase in color overlays representing an improved segmental contraction (arrow) in the same sheep 2 months after cell implantation.

The results of the 2-dimensional echocardiographic assessment for global cardiac function are summarized in Table I. The measurements were carried out 3 and 11 weeks after myocardial injury in group 3 . With a paired Student $t$ test, the 2 time points were compared within the cell-treated group. A statistical difference was found for all parameters.

Histology. Satellite cells were detected in 3 of 6 sheep 8 weeks after cell implantation by means of the skeletal isoform of adult fast MHC. This antibody did not react with healthy or cardiotoxin-injured cardiac sections, nor did it stain the type 1 fibers (slow twitch) of the skeletal muscle sections. However, the type 2 fibers (fast twitch) also present in the skeletal muscle sections stained brightly with the fast MHC antibody.
Consequently, the sheep femoral biceps from which the satellite cells were cultured expressed fast and slow myosin. Although the satellite cells were injected into the middle of the lesion with the aid of echocardiography with color kinesis, they were identified in the fibrous tissue on the periphery of the scar close to healthy cardiac tissue (Fig 3, $A, B$, and $C$ ). No skeletal muscle cells were observed in healthy myocardium.

To rule out the possibility that the detected cells with MHC could be macrophages, we tested an intercellular adhesion molecule- 1 antibody on a serial slide. An antibody nonspecific to skeletal muscle was chosen because macrophages are known to take up any type of antibody. No fluorescence was observed with the use of the intercellular adhesion molecule-1 antibody. 

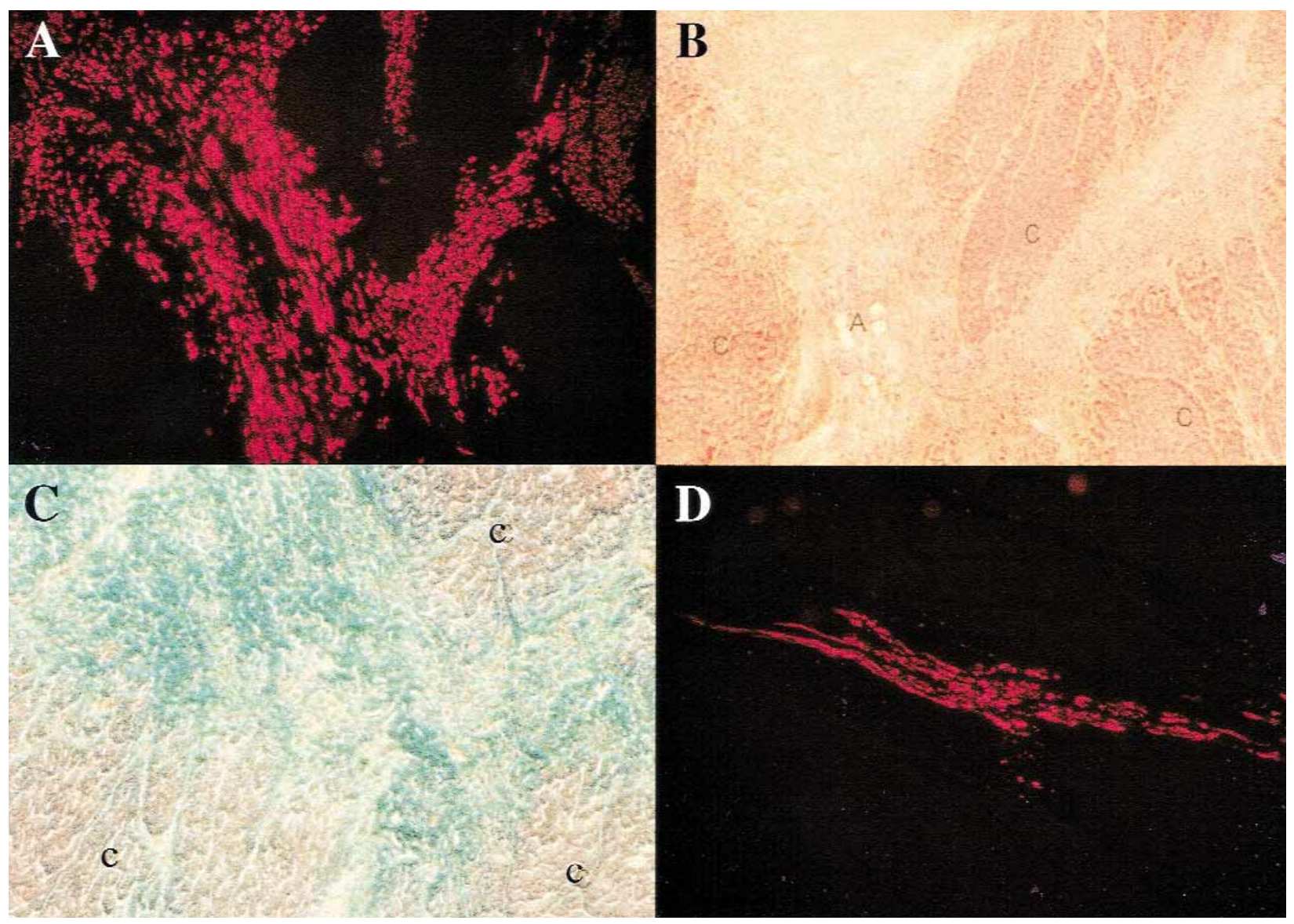

Fig 3. Serial sections of injured sheep myocardium showing implanted skeletal muscle cells (red) stained with (A) skeletal fast MHC antibodies, (B) hematein and eosin staining, and (C) Masson trichrome staining indicating cell survival in fibrous tissue (green). Adipocytes $(A)$ were present inside the lesion and cardiomyocytes $(C)$ were noted on the periphery of the lesion. D, The implanted satellite cells were also found as elongated structures resembling myotubes (magnifications $\times 10$ ).

Consequently, the cells detected with the adult fast MHC are of skeletal muscle origin with a mature phenotype.

Furthermore, elongated skeletal muscle cell structures (Fig 3,D) were observed resembling myotubes. However, the possibility that these structures were closely apposed mononucleated cells could not be ruled out by light or fluorescence microscopy.

\section{Discussion}

Myocardial injury was produced by injecting a cardiotoxin into the sheep heart muscle. The cobra toxin from Naja mossambica mossambica is known to cause muscle necrosis. ${ }^{18}$ Histologic studies showed that in the lesion, cardiomyocytes were replaced by fibroblasts and adipocytes that closely resembled dysplasia. ${ }^{19}$
Furthermore, myocardial infarction models in sheep also show a predominant fat tissue infiltration.

The cardiotoxin model was chosen over other models of myocardial lesion because it requires one single injection, produces a well-delineated transmural lesion, and reduces the risk of ventricular fibrillation. Due to the small lesion, it was possible to implant the cells throughout the whole lesion. Cryoinjury requires a freezing and a thawing time of one or more cycles and has an increased risk of ventricular fibrillation. Moreover, controversial results have been obtained with cryoinjury as to whether it creates a transmural lesion. Some investigators found that the scar was "quasi-transmural"4 and that freeze-thaw lesions consist of confluent necrosis in the subepicardium with viable myocardium in the subendocardium and are therefore not transmural ${ }^{6}$; other 
investigators reported that they had obtained a transmural scar., 911,13 The model of coronary artery ligation is complicated because of the collateral blood vessels in the sheep ventricle. Hence, the infarction has to be relatively large so that the collateral blood flow does not heal the infarcted area.

Three and 11 weeks after myocardial injury, global and regional left ventricular function were assessed. Two-dimensional echocardiography was used to define the global parameters. This method has been previously used to study the influence of neonatal muscle cells transplanted in a coronary artery ligation model in rats. ${ }^{8}$

Echocardiography with color kinesis was used for regional measurements of contraction because of the shortcomings of other methods currently used to assess the extent and severity of regional wall motion abnormalities. These methods imply a manual off-line frameby-frame tracing of the myocardial border to evaluate wall motion. Because it is often difficult to precisely define the endocardial and epicardial boundaries, these methods remain subjective. Computerized methods of edge detection are automated to a great extent. However, these methods also require off-line processing and have been successful primarily in the short-axis view. Color kinesis has been developed to facilitate the evaluation of regional wall motion. This technique tracks the motion of the endocardium in real time throughout systole and results in color-encoded images reflecting the magnitude and timing of endocardial motion. ${ }^{20}$

The regional segmental analysis of the injured myocardium revealed a significant increase in regional fractional area change from $24 \%$ to $48 \%(P<.05)$ in group 3 after cell therapy. In concordance with this result, the global functional assessment showed a statistically significant decrease in left ventricular enddiastolic and end-systolic diameters, together with a significant increase in shortening fraction and ejection fraction, which confirmed an amelioration of the left ventricular function. Therefore, a regional and global functional improvement was observed in the cell-treated group when the sheep were used as their own controls. Although the global functional improvement could be due to the cell implantation, it could also be caused by compensatory phenomena that act on the adjacent left ventricular wall close to the myocardial lesion (left ventricular remodeling process). However, the regional functional enhancement could only be brought about by the cell treatment.

In addition to the functional measurements, echocardiography with color kinesis proved to be useful to guide the syringe containing either cells or the culture media into the myocardium of a beating heart. This guiding technique led to an optimal delivery of the solutions because the needle was clearly visible on the screen, and the dispersion of the cells into the heart tissue was visualized, probably due to a contrast effect produced by the cells since the culture media only was not visible.

In 3 of the 6 sheep, cells of skeletal muscle origin could be identified by means of the skeletal isoform of an adult fast MHC antibody. In the 3 other sheep, the implanted cells could not be found. The lack of cells raises several hypotheses. First, the implanted satellite cells could have changed from a fast type to a slow type and since the antibody used to identify the cells was specific for fast type $\mathrm{MHC}$, cells producing slow type MHC could not be detected. Beside the fast MHC antibody, the cardiac sections containing implanted cells were tested with a $\beta$ MHC hybridoma (supernatant A4.951, Developmental Studies Hybridoma Bank), which is a major contractile protein in slow fibers. However, the supernatant was found not to have any cross-reactivity with sheep. Second, because primary skeletal muscle cell cultures always contain fibroblasts that tend to grow faster than satellite cells, it is possible that, of the implanted cells, the only fibroblasts that had survived were those that have been shown to improve ventricular contraction. ${ }^{21}$ Third, the occurrence of adipose tissue in the myocardial biopsy tissue made it extremely difficult to slice the mixture of tissues on a cryostat. These technical difficulties could have prevented the detection of satellite cells in all sheep.

Immunohistochemical results showed that the implanted satellite cells were not detected in the center of the scar. Persistence of the toxin in the center of the lesion has, therefore, not been excluded. Furthermore, the implanted cells did not occur in healthy myocardium. Inasmuch as satellite cells can proliferate and even migrate in response to an injury, Schultz ${ }^{22}$ and Bischoff $^{23}$ speculated that several effector molecules were released at the site of the skeletal muscle injury, which induced proliferation and migration of satellite cells during regeneration. We expected a similar cell response on injury of the myocardium. Consequently, the localization of the satellite cells, which were identified in the fibrous tissue at the periphery of the scar close to healthy cardiac tissue, suggests that the implanted cells probably have to be in the proximity of tissues that have a good blood perfusion.

We thank Dr M. Shen for the photographs and N. Goussef and M. Rancic for their laboratory assistance. We are also grateful for the collaboration of the Pathological Department at Boucicaut and Pompidou Hospitals, Paris, France. 
Received for publication May 4, 2000; revisions requested June 20, 2000; revisions received Sept 19, 2000; accepted for publication Nov 9, 2000.

Address for reprints: J.-C. Chachques, MD, PhD, Department of Cardiovascular Surgery, Broussais Hospital, 96 rue Didot, 75014 Paris, France (E-mail: j.chachques@ brs.ap-hop-paris.fr).

\section{REFERENCES}

1. Chachques JC, Grandjean P, Schwartz K, Milhaileanu S, Fardeau M, Swynghedauw B, et al. Effect of latissimus dorsi dynamic cardiomyoplasty on ventricular function. Circulation 1988;78 (Suppl):III-203-16.

2. Carpentier A, Chachques JC. Myocardial substitution with a stimulated skeletal muscle: first successful clinical case. Lancet 1985;1:1267

3. Kessler PD, Byrne BJ. Myoblast cell grafting into heart muscle: cellular biology and potential applications. Annu Rev Physiol 1999;61:219-42.

4. Marelli D, Desrosiers C, El-Alfy M, Kao RL, Chiu RC-J. Cell transplantation for myocardial repair: an experimental approach. Cell Transplant 1992;1:383-90.

5. Chiu RC-J. Using skeletal muscle for cardiac assistance. Sci Am Sci Med 1994;Nov/Dec:2-11.

6. Murry CE, Wiseman RW, Schwartz SM, Hauschka SD. Skeletal myoblast transplantation for repair of myocardial necrosis. J Clin Invest 1996;98:2512-23.

7. Dorfman J, Duong M, Zibiatis A, Pelletier MP, Shum-Tim D, Li $\mathrm{C}$, et al. Myocardial tissue engineering with autologous myoblast implantation. J Thorac Cardiovasc Surg 1998;116:744-51.

8. Scorsin M, Hagege A, Vilquin J-T, Fiszman M, Marotte F, Samuel J-L, et al. Comparison of the effects of fetal cardiomyocyte and skeletal myoblast transplantation on postinfarction left ventricular function. J Thorac Cardiovasc Surg 2000;119:116975 .

9. Taylor DA, Atkins BZ, Hungspreugs P, Jones TR, Reedy MC, Hutcheson KA, et al. Regenerating functional myocardium: improved performance after skeletal myoblast transplantation. Nat Med 1998;4:929-33.

10. Atkins BZ, Hueman MT, Meuchel J, Hutcheson KA, Glower DD, Taylor DA. Cellular cardiomyoplasty improves diastolic properties of injured heart. J Surg Res 1999;85:234-42.

11. Atkins BZ, Lewis CW, Kraus WE, Hutcheson KA, Glower DD, Taylor DA. Intracardiac transplantation of skeletal myoblasts yields two populations of striated cells in situ. Ann Thorac Surg 1999;67:124-9.

12. Atkins BZ, Hueman MT, Meuchel JM, Cottman MJ, Hutcheson KA, Taylor DA. Myogenic cell transplantation improves in vivo regional performance in infarcted rabbit myocardium. J Heart Lung Transplant 1999;18:1173-80

13. Chiu RC-J, Zibiatis A, Kao RL. Cellular cardiomyoplasty: myocardial regeneration with satellite cell implantation. Ann Thorac Surg 1995;60:12-8.
14. Kao RL, Chin TK, Ganote CE, Hossler FE, Li C, Browder W. Satellite cell transplantation to repair injured myocardium. Cardiac-Vasc Regeneration 2000;1:31-42.

15. Rajnoch C, Chachques JC, Lajos P, Fornes P, Mirochnik N, Fabiani JN, et al. Cell therapy for heart failure. Cardiovasc Surg 1998;6(Suppl 1):3.

16. Adams JE et al. Cardiac troponin-I: a marker with high specificity for cardiac injury. Circulation 1993;88:101-6.

17. Adams JE, Sicard GA, Allen BT, Bridwell KH, Lenke LG, Davila-Roman VG, et al. Diagnosis of perioperative myocardial infarction with measurement of cardiac troponin I. N Engl J Med 1994;330:670-4

18. Harris JB, Cullen MJ. Muscle necrosis caused by snake venoms and toxins. Electron Microsc Rev 1990;3:183-211.

19. Fontaine G, Fontaliran F, Zenati O, Guzman CE, Rigoulet J, Berthier J-L, et al. Fat in the heart. Acta Cardiol 1999;54:189-94.

20. Lang RM, Vignon P, Weinert L, Bednarz J, Korcarz C, Sandelski $\mathrm{J}$, et al. Echocardiographic quantification of regional left ventricular wall motion with color kinesis. Circulation 1996;93:187785.

21. Sakai T, Li RK, Weisel RD, Mickle DA, Jia ZQ, Tomita S, et al. Fetal cell transplantation: a comparison of three cell types. J Thorac Cardiovasc Surg 1999;118:715-24.

22. Schultz E, Albright DJ, Jaryszak DL, David TL. Survival of satellite cells in whole muscle transplants. Anat Rec 1988;222:12-7.

23. Bischoff R. Chemotaxis of skeletal muscle satellite cells. Dev Dyn 1997;208:505-15.

\section{Discussion}

Dr G. Hossein Almassi (Milwaukee, Wis). Dr Chachques, you alluded to the fact that these cells are basically on the periphery of the scar and dependent on the intact myocardium for survival. Do you see a role for sequential injection of these cells, as your initial implants take? Could you then proceed to the second and third injection of a very large scar, such as can happen in a large myocardial infarction?

Dr Chachques. We injected the cells in the center of the scar, and we found only cells surviving in the intermediate area. In the future, it might be interesting to inject the cells with angiogenic growth factors to improve the quality of the tissue for implantation. At this moment we are working with an endoventricular catheter to implant cells into the ventricular wall. If one injection is not enough, we can repeat this kind of therapy several times in the same patient.

Dr Carpentier. It would probably be interesting to combine these multiple injections with laser perforation from the ventricle so as to provide enough blood supply for the center. However, up to now we have not been able to see cells in the center of the necrotic area. 